\title{
Optical properties of pristine ice crystals in mid-latitude cirrus clouds: a case study during CIRCLE-2 experiment
}

\author{
J.-F. Gayet ${ }^{1}$, G. Mioche ${ }^{1}$, V. Shcherbakov ${ }^{1,2}$, C. Gourbeyre ${ }^{1}$, R. Busen ${ }^{3}$, and A. Minikin ${ }^{3}$ \\ ${ }^{1}$ Laboratoire de Météorologie Physique UMR 6016 CNRS/Université Blaise Pascal, France \\ ${ }^{2}$ LaMP - Institut Universitaire de Technologie de Montluçon, Avenue A, Briand-BP 2235, 03101 Montluçon Cedex, France \\ ${ }^{3}$ Deutsches Zentrum für Luft- und Raumfahrt, Institut für Physik der Atmosphäre, Oberpfaffenhofen, Germany
}

Received: 22 September 2010 - Published in Atmos. Chem. Phys. Discuss.: 22 October 2010

Revised: 7 February 2011 - Accepted: 25 February 2011 - Published: 17 March 2011

\begin{abstract}
In this paper, we describe in situ observations of mid-latitude cirrus cloud band carried out on 16 May 2007 during the CIRCLE-2 experiment. The Polar Nephelometer and the Cloud Particle Imager (CPI) instruments with PMS FSSP-300 and 2D-C probes were used for the description of the optical and microphysical cloud properties. Two selected cloud regions are compared and discussed in detail. Significant differences in optical properties are evidenced in terms of $22^{\circ}$ halo occurrences even though prevalent planarplate ice crystals are observed in both cloud regions. Featureless scattering phase functions are measured in the first cloud region located near the trailing edge of the cirrus-band at about $11800 \mathrm{~m} /-57^{\circ} \mathrm{C}$. In contrast, well pronounced $22^{\circ}$ halo peaks are observed with predominant similar-shaped ice crystals near the cirrus-band leading edge at $7100 \mathrm{~m} /-27^{\circ} \mathrm{C}$. CPI ice crystal images with Polar Nephelometer observations are carefully analysed and interpreted from a theoretical light scattering model in order to explain occurrence and non-occurrence of the $22^{\circ}$ halo feature. The results highlight that the halo peaks are inherent only in perfect plate ice crystals (or pristine crystals). On the basis of previous datasets in mid-latitude cirrus, it is found that simple pristine crystals are uncommon whereas particles with imperfect or complex shapes are prevalent. As a result, phase functions that are smooth and featureless best represent cirrus scattering properties.
\end{abstract}

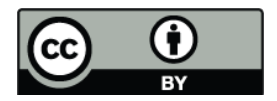

Correspondence to: J.-F. Gayet (j.f.gayet@opgc.univ-bpclermont.fr)

\section{Introduction}

Light-scattering properties of ice crystals have been the subject of considerable work over the last few years, addressing the global climate effect of cirrus clouds (Stephens et al., 1990). Optical phenomena such as the $22^{\circ}$ halo (and $46^{\circ}$ halo) were first explained by Mariotte (1717) as being due to the refraction of light (in the visible) by randomly oriented hexagonal ice crystals. Modelling studies of scattering phase functions show that these features are an indication of highly regular pristine ice crystals (see among others Takano and Liou, 1989; Iaquinta et al., 1995; Macke et al., 1996a; Yang et al., 2001; Um and McFarquhar, 2010). Observations of cloud ice particles tend to show much smoother scattering behaviour compared with modelling results obtained in laboratory studies (Sassen and Liou, 1979; Crépel et al., 1997; Barkey et al., 2002). The first in situ observations of azimuthal scattering patterns also confirmed that smooth scattering phase functions prevail in cirrus clouds (Gayet et al., 1998; Auriol et al., 2001; Field et al., 2003a; Gayet et al., 2004; Baumgardner et al., 2005). Defaults in crystal geometry, roughness of the ice surface or imperfect internal structure are known to hamper the formation of halos (see among others Baran and Labonnote, 2007). This may explain the rare ground-observed occurrences of these optical phenomena.

In this paper, we describe two cases of in situ observations in mid-latitude cirrus clouds, both having mostly planar-plate ice crystals but showing significant differences in optical properties in terms of $22^{\circ}$ halo occurrences. Surprisingly, for one case, the Polar Nephelometer data do not reveal any signature of $22^{\circ}$ (and $46^{\circ}$ ) halos although for the second case,

Published by Copernicus Publications on behalf of the European Geosciences Union. 
well-marked $22^{\circ}$ halo features are observed in a few cloud portions along with prevalent planar-plate ice crystals. The interpretation of these results is discussed in the light of a careful analysis of the ice particle morphologies and by using a theoretical model of light scattering (Shcherbakov et al., 2006a). Implications for realistic modelling of scattering properties of cirrus clouds are given.

\section{The CIRCLE-2 experiment and aircraft instrumentation}

The CIRCLE-2 campaign, held from 4 to 26 May 2007, involved the Falcon aircraft operated by DLR (Deutsches Zentrum für Luft- und Raumfahrt) from Oberpfaffenhofen (near Munich, Germany). Four independent techniques for cloud in situ measurements were installed onboard the Falcon: the PMS FSSP-300 operated by the DLR, the Cloud Particle Imager (CPI), the Polar Nephelometer (PN) and the PMS 2D-C probe, operated by the Laboratoire de Météorologie Physique (LaMP). The combination of these four techniques provides a description of particles within a diameter range varying from a few micrometers (typically $3 \mu \mathrm{m}$ ) to about $2 \mathrm{~mm}$. The method of data processing, the reliability of the instruments and the uncertainties of the derived microphysical and optical parameters have been described in detail by Gayet et al. (2009). We recall that the uncertainties on inferred microphysical parameters from 2D-C measurements are estimated to $75 \%$ and $100 \%$ on particle concentration and ice water content, respectively (Gayet et al., 2002). The accuracies on extinction coefficient and asymmetry parameters derived from the Polar Nephelometer are estimated to be within $25 \%$ and $4 \%$, respectively (Gayet et al., 2002; Jourdan et al., 2010). These accuracies could be affected by ice crystal shattering on the probe inlets. Relative humidity and vertical airspeed measurements will also be used in this study. Relative humidity was derived from measurements using a CR-2 frost point hygrometer. The derivation method of the vertical airspeed from the Falcon aircraft measurements has been described in Bögel and Baumann (1991). An error of $\pm 10 \mathrm{~cm} \mathrm{~s}^{-1}$ for a mean value within a flight path of $200 \mathrm{~km}$ (or about $20 \mathrm{~min}$ flight duration) is generally expected.

In this paper, we describe in situ observations of midlatitude cirrus cloud carried out on 16 May 2007. From MSG satellite imagery (Meteosat Second Generation) in the IR channel (not represented here) the airborne observations concerned a cirrus band associated with a warm front which moved over France. In the following, two selected cirrus cloud regions (labelled case A and case B, respectively) are compared and discussed in detail. The differences in optical cloud properties are highlighted by measuring the $22^{\circ}$ halo occurrence (or non-occurrence) with the Polar Nephelometer. These optical observations are compared with the ice particle shapes recognized from the Cloud Particle Imager data.

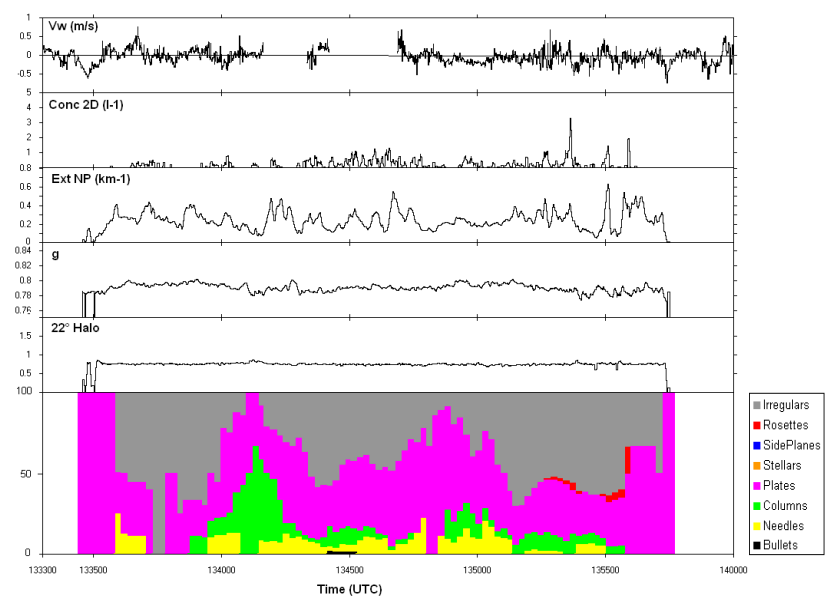

Fig. 1. Time-series of in situ parameters obtained on 16 May in cirrus cloud at $12000 /-59^{\circ} \mathrm{C}$ and $11600 \mathrm{~m} /-55^{\circ} \mathrm{C}$ levels. Vw: vertical component of the airspeed, Conc2-D: concentration of ice particles with $d>100 \mu \mathrm{m}$ (from 2D-C data), ExtNP: extinction coefficient, $g$ : asymmetry parameter, $22^{\circ}$ Halo ratio (see text) and CPI particle shape classification for ice crystals larger than $20 \mu \mathrm{m}$ (averaged over $5 \mathrm{~s}$ and expressed in percentages for each category, see legends on the right side of the series).

\section{Results}

\subsection{Cirrus properties with non-occurrence of $22^{\circ}$ halo (case A)}

A representative example of cirrus properties with nonobserved $22^{\circ}$ halo feature (case A) is illustrated from the observations carried out in a cloud region located near the trailing edge of the cirrus-band at about $11800 \mathrm{~m} /-57^{\circ} \mathrm{C}$. It should be noted that these data address the flight sequence which was coordinated with the CALIPSO overpass (13:33 UT) located to the west of France over the ocean. The comparison results between the CALIPSO products and in situ observations has been thoroughly described and interpreted by Mioche et al. (2010). Figure 1 represents the timeseries of the vertical component of the airspeed and cloud parameters: the concentration of ice particles with $d>50 \mu \mathrm{m}$ (from 2D-C data), the extinction coefficient, the asymmetry parameter and the halo ratio (these two last parameters being inferred from the Polar Nephelometer measurements). The halo ratio is not an optical parameter, but rather a quantitative criterion to characterise the occurrence of the $22^{\circ}$ halo peak. This criterion is defined by the ratio of the scattered energy values measured at the scattering angles of $22^{\circ}$ and $18.5^{\circ}$ (Auriol et al., 2001). High halo ratio values $(>1.0)$ correspond to sharp peaks with a well-pronounced $22^{\circ}$ halo, whereas smoothed peaks and/or smoothed scattering phase functions with no $22^{\circ}$ halo feature are characterised by a smaller halo ratio $(<1)$. The sampling levels were located near the cirrus cloud top: $12000 \mathrm{~m} /-59^{\circ} \mathrm{C}$ (from 13:30 

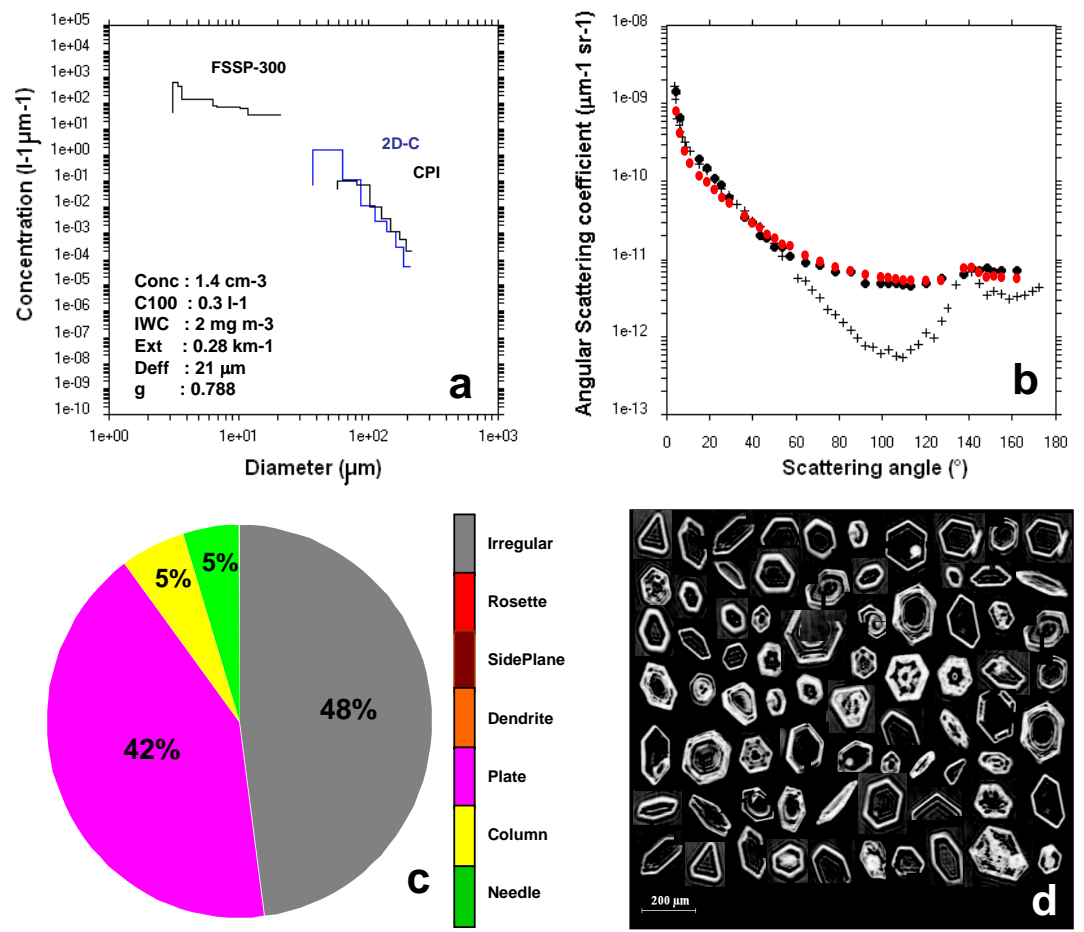

Fig. 2. Mean cirrus cloud properties averaged between 13:32:15 and 13:47:20 (see Fig. 1). (a) FSSP-300, 2D-C (blue) and CPI (black) particle size distributions with averaged values of microphysical and optical parameters; (b) scattering phase function measured by the Polar Nephelometer (filled black circle symbols) and theoretical phase function (cross symbols) calculated from the FSSP-300 size distribution assuming (spherical) ice crystals. Filled red circles are modelled points (Shcherbakov et al., 2006a) from observed crystal shapes (see discussion in Sect. 4). (c) Pie-chart representation of the averaged particle shape classification (in terms of surface particle); (d) illustrative examples of ice particle images from the CPI instrument.

to $13: 45$ ) and $11600 \mathrm{~m} /-55^{\circ} \mathrm{C}$ (from $13: 47$ to $13: 57$, see Fig. 1). The results show that the extinction coefficient is $0.3 \mathrm{~km}^{-1}$ on average, whereas the ice particle concentration detected by the $2 \mathrm{D}-\mathrm{C}$ reaches only 1 to $31^{-1}$. The asymmetry parameter and the halo ratio exhibit very small horizontal variations indicating homogeneous optical properties. Mean properties (averaged between 13:32:15 and 13:47:20) are displayed in Fig. 2. The upper left panel shows the mean particle size distributions of the FSSP-300, 2D-C and CPI, whereas the upper right panel represents the scattering phase function (without normalization in units of $\mu \mathrm{m}^{-1} \mathrm{sr}^{-1}$ ) measured by the Polar Nephelometer (filled black circle symbols) and the theoretical phase function (cross symbols) calculated from the FSSP-300 size distribution assuming (spherical) ice crystals. The modelling results from observed crystal shapes are shown by solid red circles (see related discussion in Sect. 4 below). The mean values of the parameters indicate ice particle concentration $\left(1.4 \mathrm{~cm}^{-3}\right)$, concentration of particle with $d>100 \mu \mathrm{m}\left(0.31^{-1}\right)$, ice water content $\left(2 \mathrm{mg} \mathrm{m}^{-3}\right)$, extinction coefficient $\left(0.28 \mathrm{~km}^{-1}\right)$, effective diameter $(21 \mu \mathrm{m})$ and asymmetry parameter $(0.788)$. We note in passing that the effective diameter is defined by the volume to surface ratio (Gayet et al., 2004) and relate contributions of ice particles measured above $3 \mu \mathrm{m}$ (from FSSP-300 and 2D$\mathrm{C}$ instruments). The observed and the theoretical phase functions (see upper right panel) show close agreement at the forward scattering angles $\left(5^{\circ}-50^{\circ}\right)$. This proves the consistency of data from the FSSP-300 (assuming the geometric optics limit) and Polar Nephelometer instruments, because most of the extinction is caused by scattering at forward angles. According to Field et al. (2003b) and Heymsfield (2007), the FSSP-300 and Polar Nephelometer measurements are not likely to be strongly affected by ice crystal-shattering effects since the recorded ice particles are quite small (the effective diameter is of $21 \mu \mathrm{m}$ and the largest particles are less than $250 \mu \mathrm{m}$ in size).

In Fig. 1, the time-series of the CPI particle shape classification for ice crystals larger than $25 \mu \mathrm{m}$ has been superimposed (averaged over $5 \mathrm{~s}$ due to low particle concentration and expressed in percentages for each category). The LaMP software (Lefèvre, 2007) was used to process CPI images to provide information on the ice-particle morphology. The results show that plate ice crystals dominate the ice crystal shape in the whole reported cloud sequence. Such plate ice crystals could be horizontally oriented (Bréon and Dubrulle, 2004) which may therefore explain, for that 
particular cirrus situation, the significant overestimation of the retrieved CALIPSO extinction with regards to coordinated in situ observations (Mioche et al., 2010). We note in passing that not only plate ice crystals could explain the high level of CALIOP backscattering in cirrus clouds. Such a feature could also be due to pristine-crystals like elongated columns, needles (and thin plates) which are preferentially oriented with their greater projected areas facing the fall direction (see former studies: Ono, 1969; Platt, 1978; Takano and Jayaweera, 1985). On the bottom left panel in Fig. 2, pie-chart representation of the average particle shape classification (in terms of particle surface) reveals $42 \%$ plates, $10 \%$ needles and columns with $48 \%$ unclassified particles (irregular) as illustrated by examples of ice particle images (see bottom right panel). Even with the prevalence of regular plate-shaped ice crystals, the Polar Nephelometer surprisingly does not reveal any signature of the $22^{\circ}$ halo with a featureless scattering phase function as highlighted in Fig. 2 with a halo ratio of 0.74 . It should be noted that this feature is not a consequence of the preferential orientation of plate-like crystals because the orientation is lost inside the shrouded Polar Nephelometer (and CPI) inlet due to aerodynamical disturbances (King, 1986). Therefore, randomly oriented plate-like crystals should have caused a sharp peak in the forward scattering properties related to the $22^{\circ}$ halo (see among others Yang et al., 2001) which is not observed in this case.

A counterexample is discussed in the next section which describes cirrus properties with a well-marked $22^{\circ}$ halo peak still related to plate-like ice crystals.

\subsection{Cirrus properties with $22^{\circ}$ Halo occurrence (case B)}

This example (case B) concerns a cirrus cloud sampled over France during the DLR Falcon transit flight from Oberpfafenhoffen to Brest (France). The observations were carried out in a region located near the leading edge of the cirrus band at $7100 \mathrm{~m} /-27^{\circ} \mathrm{C}$ flight level. Time-series of the same parameters as in Fig. 1 with relative humidity (over ice) are displayed in Fig. 3. Compared with the previous example, the cirrus cloud is denser with rather high horizontal heterogeneities. The extinction coefficient and the ice particle concentration peak at $4.8 \mathrm{~km}^{-1}$ and $50 \mathrm{l}^{-1}$, respectively, while the asymmetry parameter and the halo ratio reveal large variations (from 0.77 to 0.80 and from 0.5 to 1.4 , respectively). These variations, when compared to the CPI particle shape classification for ice crystals, highlight that high halo ratios $\left(22^{\circ}\right.$ halo peaks) are observed with the largest occurrence of plate ice crystals (see arrows in Fig. 3). In order to illustrate this feature the mean properties (averaged between 09:02:10 and 09:02:30, i.e., during $20 \mathrm{~s}$, see Fig. 3) are displayed in Fig. 4. As for Fig. 2, the upper panels display the mean particle size distributions and measured scattering phase function along with the theoretical phase

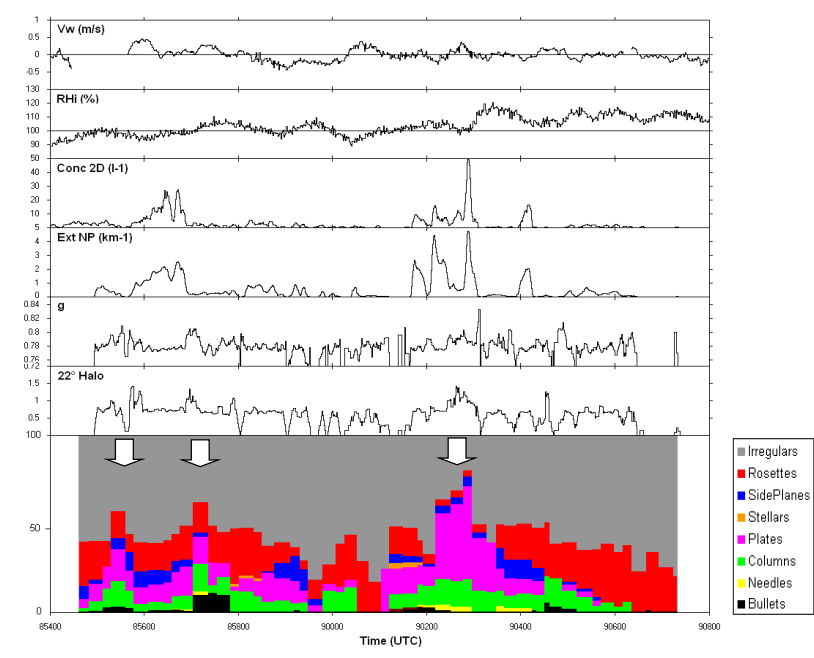

Fig. 3. Same as in Fig. 1. Time-series of in situ parameters obtained on 16 May in cirrus cloud at $7200 \mathrm{~m} /-27^{\circ} \mathrm{C}$. The relative humidity (over ice) is also indicated.

function calculated from the FSSP-300 size distribution. At forward angles (see upper right panel) the observed energy (from the Polar Nephelometer) is larger than the theoretical phase function derived from FSSP-300 data indicating a significant contribution of particles larger than $20 \mu \mathrm{m}$ on the scattering pattern. As for the previous case, the modelling results from observed crystal shapes are shown by solid red circles in Fig. 4 (see related discussion in Sect. 4 below). The mean values of the parameters indicate the ice particle concentration $\left(1.9 \mathrm{~cm}^{-3}\right)$, the concentration of particles with $d>100 \mu \mathrm{m}\left(7.3 \mathrm{l}^{-1}\right)$, the ice water content $\left(14 \mathrm{mg} \mathrm{m}^{-3}\right)$, the extinction coefficient $\left(0.49 \mathrm{~km}^{-1}\right)$, the effective diameter $(86 \mu \mathrm{m})$ and the asymmetry parameter $(0.795)$. Within this cloud sequence the Polar Nephelometer clearly reveals the $22^{\circ}$ halo peak which remarkably occurs with mostly pristine plate-shaped ice crystals. Indeed, the pie-chart (see bottom left panel in Fig. 4) reveals contributions of 57\% plates, $17 \%$ columns and needles, $12 \%$ of dendrite and side plane with only $15 \%$ unclassified (irregular). Compared to the previous classification in Fig. 2, the smaller proportion of unclassified shapes is explained by larger ice crystals $(86 \mu \mathrm{m}$ versus $21 \mu \mathrm{m}$, respectively) due to more reliable shape recognition. The plate type is found to be the dominant ice crystal shape for both examples with rather similar occurrences (57\% versus $42 \%$, respectively).

As larger ice crystals are observed in this case (crystal sizes up to $1 \mathrm{~mm}$ ), the FSSP-300 and Polar Nephelometer measurements are likely to be more affected by ice crystal shattering effects than in the previous cirrus case. From a modelling approach (Shcherbakov et al., 2010), rough estimates of subsequent errors on extinction and particle concentration could be estimated as $35 \%$ and $70 \%$, respectively. Nevertheless, a visual analysis of the CPI images (see 

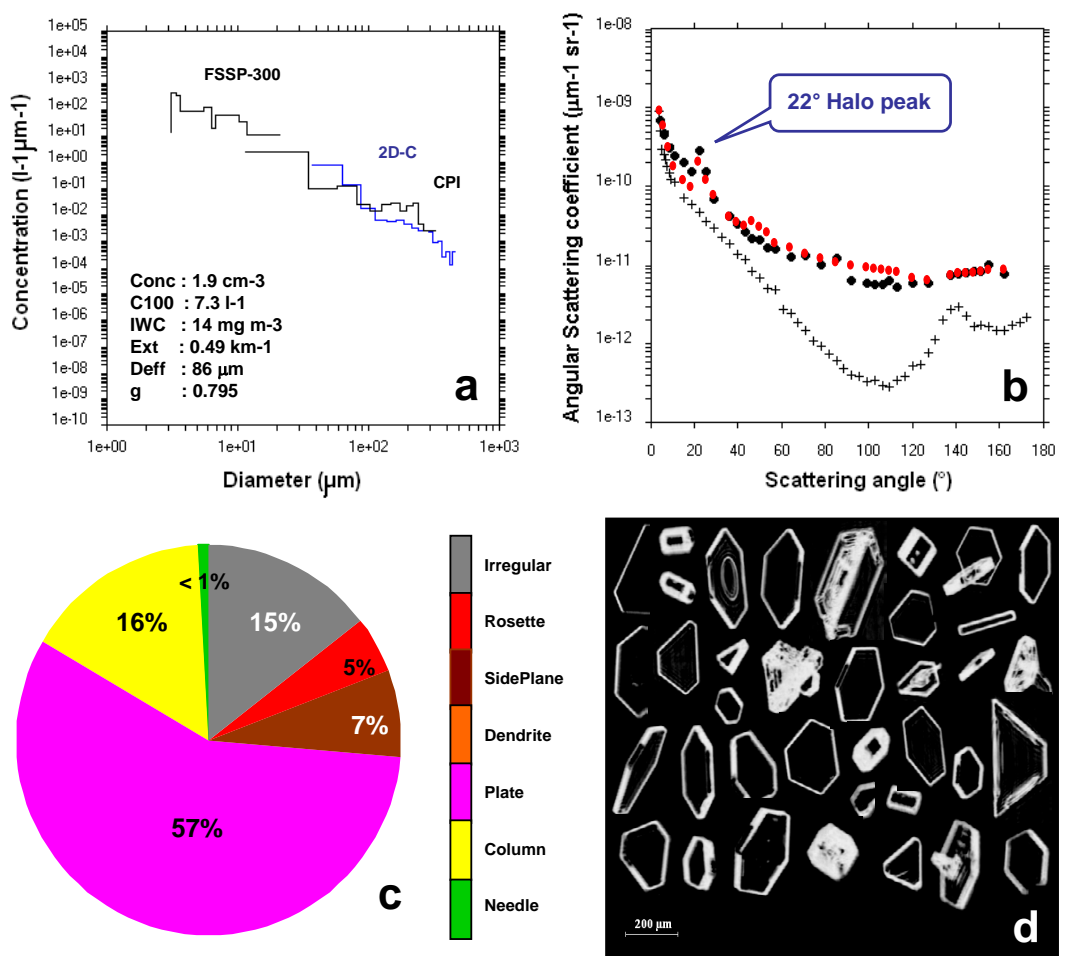

Fig. 4. Same as in Fig. 2. Mean cirrus cloud properties averaged between 09:02:10 and 09:02:30 (see Fig. 3).

examples in Fig. 4d) clearly suggests that most of the sampled ice crystals are intact with a quasi-perfect shape and a dense internal structure. Such a robust feature may be less sensitive to the particle shattering.

\section{Discussion}

The prevalence of plate ice crystals is a common feature of both the examples given above. At the same time, larger ice crystals are observed for case B. This is seen in Fig. 5a which displays the halo ratio versus the mean volume diameter (MVD) derived from the CPI size distributions. Wellmarked $22^{\circ}$ halo peaks (halo ratio > 1) are found for $M V D$ ranging from 50 to $250 \mu \mathrm{m}$. Case A data (non-halo case) represented by red symbols are distributed over a smaller $M V D$ range $(<130 \mu \mathrm{m})$ and with sizes larger than $20 \mu \mathrm{m}$. This size appears to delineate the lower limit of ice crystal size responsible (at visible wavelengths) for halo formation according to earlier laboratory studies (Sassen and Liou, 1979; Barkey et al., 2002) and theoretical results (Mishchenko and Macke, 1999). In situ observations at the South Pole station (Shcherbakov et al., 2006a; Lawson et al., 2006) also reported very well-marked $22^{\circ}$ halo peaks with pristine ice crystals no larger than $100 \mu \mathrm{m}$. Therefore, the reported ice crystal sizes do not appear to be critical for the halo/no-halo interpretation.
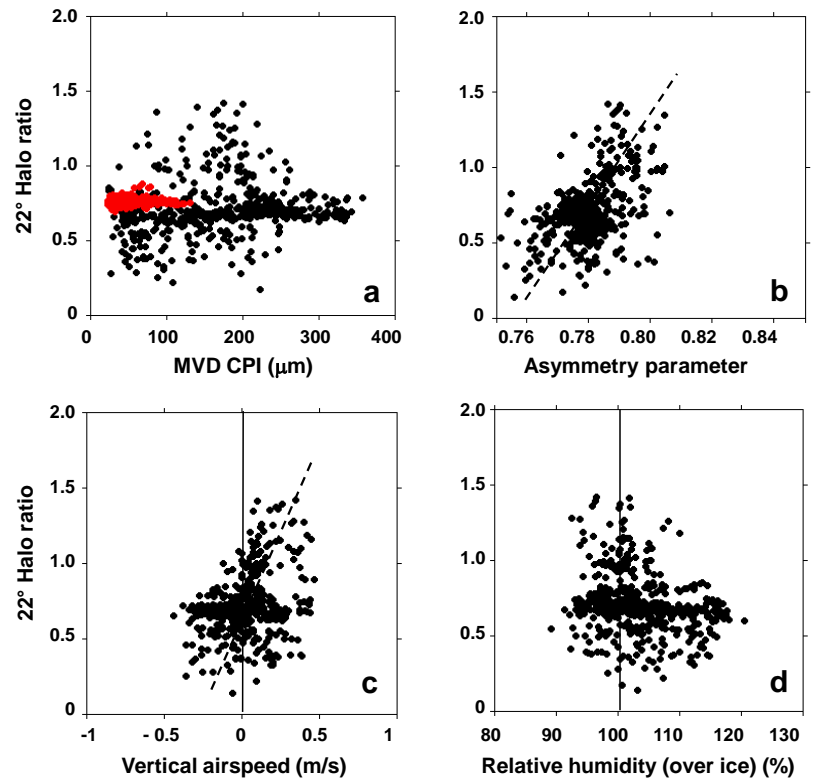

Fig. 5. Scatter plots of the halo ratio versus: (a) the mean volume diameter from CPI (DVM), (b) the asymmetry parameter, (c) the relative humidity over ice and (d) the vertical airspeed. The data relate cirrus with $22^{\circ}$ Halo occurrence (case B, see Fig. 3). The red points in Fig. 5a concern the cirrus with no $22^{\circ}$ Halo occurrence (case A, see Fig. 1). 
Quite regular plate-shaped ice particles are highlighted from CPI images in Figs. 2d and 4d. Most of the recorded ice crystal plates in Fig. 4d have the perfectly transparent internal structure. Thus, refraction through the $60^{\circ}$ prisms of such plates will produce a sharp scattering peak near $22^{\circ}$ (see Fig. 4b). On the contrary, plate-shaped ice particles in Fig. 2d have an imperfect internal structure with well recognizable lattices. As a result, the measured phase function in Fig. $2 b$ is smooth and featureless. Our data and model calculations show that the halo feature is only observed for perfect plate ice crystals (or pristine crystals, strictly speaking). This also means that the Polar Nephelometer data contains a signature of pristine ice crystals. Defaults in crystal geometry, roughness of the ice surface or imperfect internal structure do hamper the formation of halo (see among others Baran and Labonnote, 2007). The model from Shcherbakov et al. (2006a) has been employed to compute the angular scattering patterns by using measured crystal shape and size and by considering both roughness and internal structure. In this model, the surface roughness assumes the Weibull statistics and the air bubble density is hypothesized to represent the internal heterogeneities of the crystal. Ice plates and columns were modelled by quasi-hexagonal prisms with the aspect ratio of 0.2 and 2, respectively. To smooth the $46^{\circ}$ halo peak, the hexagonal planes were divided into a number of facets. Furthermore, the vertices of the facets were randomly shifted along the "C" axis of the crystal. The shift was within $10 \%$ of the crystal length. The particle shape classification was considered in terms of particle surface (see pie-charts in Figs. 2c and 4c). The fitting results are shown using red points in Figs. $2 \mathrm{~b}$ and $4 \mathrm{~b}$. The smoothed scattering pattern (Fig. 2b) was obtained from the very rough surface of crystals with a heavy load of inclusions. To be specific, the distortion parameter was of 0.1 , which corresponds to a deeply rough surface according to the classification of Yang and Liou (1998); the mean free path length between two subsequent inclusions (see details in Macke et al., 1996b) was equal to $0.15 \times D$, where $D$ is the diameter of the circle circumscribing the hexagonal facet of an ice crystal. The scattering pattern with $22^{\circ}$ halo (Fig. $4 \mathrm{~b}$ ) was computed for the slightly rough surface of crystals that have no inclusions (the distortion parameter was of 0.01 ).

The azimuthal halo pattern of the scattering behaviour significantly enhances the asymmetry parameter as exemplified in Fig. 5b. The larger $g$ (from 0.780 to 0.805 ) is more pronounced in the $22^{\circ}$ halo peak $(0.74<$ halo ratio $<1.50)$, simply because the energy is scattered more in the forward direction. Highly regular or pristine ice crystals are expected to result from extremely regular crystal growth. Figure $5 \mathrm{c}$ and d displays the scatter plots of the halo ratio versus relative humidity (over ice) and vertical airspeed, respectively. Figure $5 \mathrm{c}$ reveals that the $22^{\circ}$ halo peaks are distributed mostly at around $100 \%$ of RHi and confirm the findings from Heymsfield (1986) and Pruppacher and Klett (1997) that low ice supersaturations are known to favour regular and slow crystal growth. This feature should be found in low updraft velocities, but results in Fig. 5d rather show that halo ratios are more pronounced for increasing updrafts.

Coming back to Fig. 3, pristine ice crystals (CPI images) with subsequent $22^{\circ}$ halo signature (PN) are observed in only a few cloud portions (see arrows) characterised by small horizontal scales (from $1000 \mathrm{~m}$ to $4000 \mathrm{~m}$ ). The large dataset obtained during the INCA experiment (Gayet et al., 2004) showed that cloud sections with the occurrence of the halo signature (and, therefore, pristine ice crystals) occurred statistically in only $3 \%$ of the total measurement time in mid-latitude cirrus (Auriol et al., 2001; Shcherbakov et al., 2006b). Korolev et al. (2000) also observed a similar low occurrence (3\%) of pristine ice particles in Arctic clouds (with temperatures lower than $-30^{\circ} \mathrm{C}$ ) from the analysis of CPI data. This means that while simple pristine crystals are uncommon, particles with imperfect or complex shapes (shape defaults, roughness, inclusions, ...) are prevalent. Following the findings of Baran $(2004,2009)$ modelling of ice crystal ensemble rather than single crystals should better represent cirrus single-scattering properties. Our large dataset in cirrus (at mid-latitudes) clearly shows that phase functions are smooth and featureless and best represent scattering properties from cirrus.

As for the observed differences in the crystal internal structure properties, they may likely be explained by dominant crystal growth regimes, i.e., mainly inhomogeneous in the trailing edge parts of the cirrus band and locally regular and slow in the leading edge cirrus region. It should be noted that no significant differences between the origins of the air masses in the two experienced cirrus regions have been found from the HYSPLIT back trajectory analysis (NOAA Hybrid Single-Particle Lagrangian Integrated Trajectory model, Draxler and Rolph, 2003). Despite the inherent limitations in the reliability of the results, the analysed backward trajectories provide at least some basis for speculation that similar IN were present in both cases which would not explain the differences in the observed ice crystal internal structure.

\section{Conclusions}

Two regions within a cirrus band associated with a warm front over France have been analysed from airborne in situ measurements. The comparisons between these cloud parts show significant differences in optical properties in terms of $22^{\circ}$ halo occurrences even though prevalent planar-plate ice crystals are observed in both cloud regions. Featureless scattering phase functions are measured in the first cloud part located near the trailing edge of the cirrus-band near $11800 \mathrm{~m} /-57^{\circ} \mathrm{C}$. A careful analysis of the ice particle morphologies from CPI data highlights that plate-shaped ice particles have, in this case, an imperfect internal structure with well recognizable lattices. In contrast, well pronounced $22^{\circ}$ halo peaks are observed in the second selected region located 
near the cirrus-band leading edge at $7100 \mathrm{~m} /-27^{\circ} \mathrm{C}$. Here most of the recorded ice crystal plates have a perfectly transparent internal structure. Thus, refraction through the $60^{\circ}$ prisms of such plates will produce a sharp scattering peak near $22^{\circ}$. The occurrence and non-occurrence of the $22^{\circ}$ halo feature is interpreted from a theoretical light scattering model which considers measured crystal shape and size with both roughness and internal structure. Our data and model calculations show that the halo feature is only observed for perfect plate ice crystals (or pristine crystals, strictly speaking). This also means that the Polar Nephelometer data contain a signature of pristine ice crystals. Defaults in crystal geometry, roughness of the ice surface or imperfect internal structure hamper the formation of halo.

Pristine ice crystals causing a $22^{\circ}$ halo signature are observed in only a few cloud portions characterised by small horizontal scales (from $1000 \mathrm{~m}$ to $4000 \mathrm{~m}$ ) and confirm previous observations in cirrus and in Arctic clouds. Cloud sections with the occurrence of the halo signature (and, therefore, pristine ice crystals) occur statistically in only $3 \%$ of the total measurement time in mid-latitude cirrus. Therefore, it is found that simple pristine crystals are uncommon, whereas particles with imperfect or complex shapes are prevalent in mid-latitude cirrus clouds. As a result, phase functions are smooth and featureless and best represent cirrus scattering properties.

The results presented in this paper also show that the combination of the Polar Nephelometer and the Cloud Particle Imager leads to a valuable interpretation of the interactions between optical properties and ice particle morphologies in cirrus cloud. They confirm the findings of Jourdan et al. (2010) from a detailed in situ characterisation of the microphysical and optical properties of an Arctic mixed phase cloud.

Acknowledgements. This work was funded by the Centre National d'Etudes Spatiales (CNES) and by a grant from the CNRS/INSU. The contribution of DLR as well as a large part of Falcon flight hours was funded in the framework of the DLR PAZI-2 project. We thank the members of DLR (Deutsches Zentrum für Luft- und Raumfahrt) who organized the experiment management and aircraft operations. We are grateful to A. Dörnbrack (DLR) for providing meteorological analysis from the ECMWF model. We acknowledge A. Schwarzenboeck and J.-F. Fournol (LaMP), B. Weinzierl and H. Rüba (DLR) for their active participation to the CIRCLE-2 experiment, and K. James, who reviewed the manuscript. The authors gratefully acknowledge the NOAA Air Resources Laboratory (ARL) for the provision of the HYSPLIT transport and dispersion model and READY Web site (http://www.arl.noaa.gov/ready.html) used in this publication. We thank the anonymous reviewers who made important comments which strengthened the manuscript.

Edited by: T. Garrett

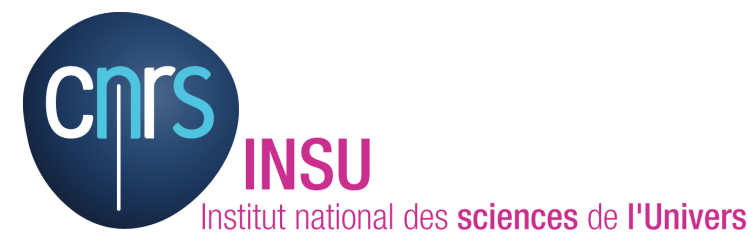

The publication of this article is financed by CNRS-INSU.

\section{References}

Auriol, F., Gayet, J.-F., Febvre, G., Jourdan, O., Labonnote, L., and Brogniez, G.: In situ observations of cirrus cloud scattering phase function with $22^{\circ}$ and $46^{\circ}$ halos: Cloud field study on 19 February 1998, J. Atmos. Sci., 58, 3376-3390, 2001.

Baran, A. J.: On the scattering and absorption properties of cirrus cloud, J. Quant. Spect. Rad. Tran., 89, 17-36, 2004.

Baran, A. J.: A review of the light scattering properties of cirrus, J. Quant. Spect. Rad. Tran., 110, 1239-1260, 2009.

Baran, A. J. and Labonnote, L.-C.: A self-consistent scattering model for cirrus, I: The solar region, Q. J. Roy. Meteorol. Soc., 133, 1899-1912, 2007.

Barkey, B., Bailey, M., Liou, K.-N., and Hallett, J.: Light-scattering properties of plate and column ice crystals generated in a laboratory cold chamber, Appl. Optics, 41, 5792-5796, 2002.

Baumgardner, D., Chepfer, H., Raga, G. B., and Kok, G. L.: The shapes of very small cirrus particles derived from in situ measurements, Geophys. Res. Lett., 32, L01806, doi:10.1029/2004GL021300, 2005.

Bögel, W. and Baumann, R.: Test and calibration of the DLR Falcon wind measuring system by maneuvers, J. Atmos. Oceanic Technol., 8, 5-18, 1991.

Bréon, F. M. and Dubrulle, B.: Horizontally oriented plates in clouds, J. Atmos. Sci., 61, 2889-2898, 2004.

Crépel, O., Gayet, J.-F., Fournol, J.-F., and Oshchepkov, S.: A new airborne Polar Nephelometer for the measurement of optical and microphysical cloud properties, Part II: Preliminary tests, Ann. Geophys., 15, 460-470, doi:10.1007/s00585-997-0460-0, 1997.

Draxler, R. R. and Rolph, G. D.: HYSPLIT (Hybrid SingleParticle Lagrangian Integrated Trajectory) model, Air Resour. Lab., NOAA, Silver Spring, Md., available at: http://ready.arl. noaa.gov/HYSPLIT.php (last access: 16 March 2011), 2003.

Field, P. R., Baran, A. J., Kaye, P. H., Hirst, E., and Greenaway, R.: A test of cirrus ice crystal scattering phase functions, Geophys. Res. Lett., 30, 1752, doi:10.1029/2003GL017482, 2003a.

Field, P. R., Wood, R., Brown, P. R. A., Kaye, P. H., Hirst, E., Greenaway, R., and Smith, J. A.: Ice particle interarrival times measured with a fast FSSP, J. Atmos. Oceanic Technol., 20, 249261, 2003 b.

Gayet, J.-F., Auriol, F., Oshchepkov, S., Schröder, F. , Duroure, C., Febvre, G., Fournol, J.-F., Crépel, O., Personne, P., and Daugero, D.: In situ measurements of the scattering phase function of stratocumulus, contrails and cirrus, Geophys. Res. Lett., 25, 971974, 1998.

Gayet, J.-F., Asano, S., Yamazaki, A., Uchiyama, A., Sinyuk, A., Jourdan, O., and Auriol, F.: Two case studies of winter continental -type water and mixed-phase stractocumuli over the sea, Part I: Microphysical and optical properties, J. Geophys. Res., 107(D21), 4569, doi:10.1029/2001JD001106, 2002. 
Gayet, J.-F., Ovarlez, J., Shcherbakov, V., Ström, J., Schumann, U., Minikin, A., Auriol, F., Petzold, A., and Monier, M.: Cirrus cloud microphysical and optical properties at southern and northern midlatitudes during the INCA experiment, J. Geophys. Res., 109, D20206, doi:10.1029/2004JD004803, 2004.

Gayet, J.-F., Mioche, G., Dörnbrack, A., Ehrlich, A., Lampert, A., and Wendisch, M.: Microphysical and optical properties of Arctic mixed-phase clouds, the 9 April 2007 case study., Atmos. Chem. Phys., 9, 6581-6595, doi:10.5194/acp-9-6581-2009, 2009.

Heymsfield, A. J.: Ice particles observed in a cirriform cloud at $-83^{\circ} \mathrm{C}$ and implications for polar stratospheric clouds, J. Atmos. Sci., 43, 851-855, 1986.

Heymsfield, A. J.: On measurements of small ice particles in clouds, Geophys. Res. Lett., 34, L23812, doi:10.1029/2007GL030951, 2007.

Iaquinta, J., Isaka, H., and Personne, P.: Scattering phase function of bullet rosette ice crystals, J. Atmos. Sci., 52, 1401-1413, 1995.

Jourdan, O., Mioche, G., Garret, T. J., Schwarzenbock, A., Vidot, J., Xie, Y., Shcherbakov, V., Duroure, C., Yang, P., and Gayet, J.-F.: Coupling of the microphysical and optical properties of arctic clouds during the ASTAR 2004 experiment: Implications for light scattering modelling, J. Geophys. Res., 115, D23206, doi:10.1029/2010JD014016, 2010.

King, W. D.: Air flow and particle trajectories around aircraft fuselages. IV: Orientation of ice crystals, J. Atmos. Ocean. Tech., 3, 433-439, 1986.

Korolev, A. V., Isaac, G., and Hallett, J.: Ice particle habits in Arctic clouds, Geophys. Res. Lett., 26, 1299-1302, 2000.

Lawson, P., Baker, B., Zmarzly, P., O'Connor, D., Mo, Q., Gayet, J.-F., and Shcherbakov, V.: Microphysical and optical properties of ice crystals at South Pole Station, J. Appl. Meteor. Climatol., 45(11), 1505-1524, doi:10.1175/JAM2421.1, 2006.

Lefèvre, R.: Physique de la mesure de la sonde CPI pour la mesure des propriétés des cristaux de glace, Application aux observations réalisées durant la campagne ASTAR 2004, Université Blaise Pascal, Aubière, France, 186 pp., 2007.

Mariotte, E.: Oeuvres de Mr. Mariotte, Traité des couleurs, 1, P. Vander, Ed., 272-281, 1717.

Macke, A., Mueller, J., and Raschke, E.: Single scattering properties of atmospheric ice crystals, J. Atmos. Sci., 53, 2813-2825, 1996 .

Macke, A., Mishchenko, M. I., and Cairns, B.: The influence of inclusions on light scattering by large ice particles, J. Geophys. Res., 101, 23311-23316, 1996b.

Mishchenko, M. I. and Macke, A.: How big should hexagonal ice crystals be to produce halos?, Appl. Opt., 38, 1626-1629, 1999.

Mioche, G., Josset, D., Gayet, J.-F., Pelon, J., Garnier, A., Minikin, A., and Schwarzenboeck, A.: Validation of the CALIPSO/CALIOP extinction coefficients from in situ observations in mid-latitude cirrus clouds during CIRCLE-2 experiment, J. Geophys. Res., 115, D00H25, doi:10.1029/2009JD012376, 2010.
Ono, A.: The Shape and Riming Properties of Ice Crystals in Natural Clouds, J. Atmos. Sci., 26, 138-147, 1969.

Platt, C. M. R.: Lidar Backscatter from Horizontal Ice Crystal Plates, J. Appl. Meteor., 17, 482-488, 1978.

Pruppacher, H. R. and Klett, J. D.: Microphysics of Clouds and Precipitation, Kluwer Academic, 954 pp., 1997.

Sassen, K. and Liou, K. N.: Scattering of polarized laser light by water droplets, mixed phase and ice clouds, Part I: Angular scattering patterns, J. Atmos. Sci., 36, 838-851, 1979.

Shcherbakov, V., Gayet, J.-F., Baker, B. and Lawson, P.: Light scattering by single natural ice crystals, J. Atmos Sci., 63(5), 1513$1525,2006 a$

Shcherbakov V., Gayet, J.-F., Jourdan, O., Ström, J., and Minikin, A.: Light scattering by single ice crystals of cirrus clouds, Geophys.. Res. Lett., 33(15), L15809, doi:10.1029/2006GL026055, 2006b.

Shcherbakov, V., Gayet, J.-F., Febvre, G., Heymsfield, A. J., and Mioche, G.: Probabilistic model of shattering effect on in-cloud measurements, Atmos. Chem. Phys. Discuss., 10, 11009-11045, doi:10.5194/acpd-10-11009-2010, 2010.

Stephens, G. L., Tsay, S. C., Stackhouse, P. W., and Flatau, P. J.: The relevance of the microphysical and radiative properties of cirrus clouds to climate and climate feedback, J. Atmos. Sci., 47, 1742-1753, 1990.

Takano, Y. and Jayaweera, K.: Scattering phase matrix for hexagonal ice crystals computed from ray-tracing, Appl. Opt., 24, 32543263, 1985.

Takano, Y. and Liou, K. N.: Solar radiative transfer in cirrus clouds, Part I: single-scattering and optical properties of hexagonal ice crystals, J. Atmos. Sci., 45, 3-19, 1989.

Um, J. and McFarquhar, G. M.: Dependence of the singlescattering properties of small ice crystals on idealized shape models, Atmos. Chem. Phys. Discuss., 10, 28109-28149, doi:10.5194/acpd-10-28109-2010, 2010.

Yang, P. and Liou, K. N.: Single-scattering properties of complex ice crystals in terrestrial atmosphere, Contr. Atmos. Phys., 71, 223-248, 1998.

Yang, P., Gao, B. C., Baum, B. A., Wiscombe, W. J., Hu, Y. X., Nasiri, S. L., Soulen, P. F., Heymsfield, A. J., McFarquhar, G. M., and Miloshevisch, L. M.: Sensitivity of cirrus bidirectional reflectance to vertical inhomogeneity of ice crystal habits and size distributions for Moderate-Resolution Imaging Spectroradiometer (MODIS) bands, J. Geophys. Res., 106, 17267-17291, 2001. 